\title{
Etiology, risk factors and management of implant fractures
}

\author{
Arturo Sánchez-Pérez ${ }^{1}$, Mª José Moya-Villaescusa ${ }^{1}$, Alfonso Jornet-García ${ }^{1}$, Santiago Gomez ${ }^{2}$ \\ ${ }^{1}$ Head of the Periodontics, Associated Professor of the Periodontics Collaborating, Professor of the Periodontics Unit, Murcia \\ (Spain) \\ ${ }^{2}$ Assistant Professor of the Histology Unit Departamento de Anatomía Patológica Universidad de Cádiz Facultad de Medicina
}

Correspondence:

Unidad de Periodoncia

Universidad de Murcia

Clínica Odontológica Universitaria,

C/ Marqués de los Vélez s/n $2^{a}$ Planta

30008 - Murcia Spain

arturosa@um.es

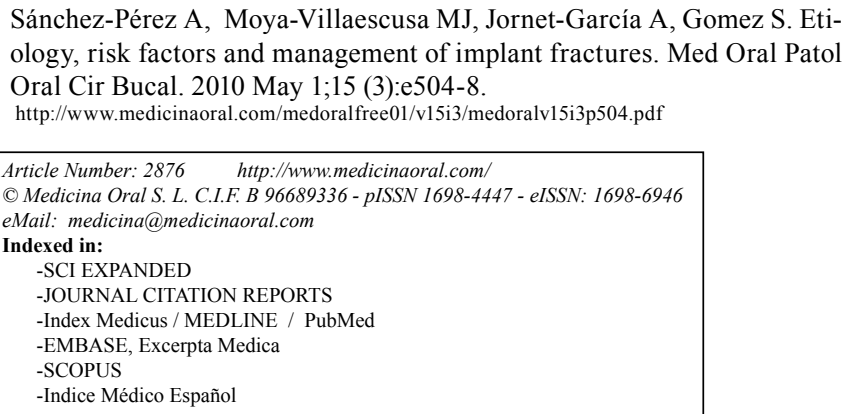

\begin{abstract}
Implant fracture is an infrequent and late biomechanical complication with a serious clinical outcome. In effect, such fractures pose important problems for both the patient and the dental surgeon. According to most literature sources, the prevalence of dental implant fractures is very low (approximately 2 fractures per 1000 implants in the mouth). Considering that implant placement is becoming increasingly popular, an increase in the number of failures due to late fractures is to be expected. Clearly, careful treatment can contribute to reduce the incidence of fracture. An early diagnosis of the signs alerting to implant fatigue, such as loosening, torsion or fracture of the post screws and prosthetic ceramic fracture, can help prevent an undesirable outcome. The present literature review describes the management options and discusses the possible causal mechanisms underlying such failures, as well as the factors believed to contribute to implant fracture.
\end{abstract}

Key words: Dental implants, implant fracture, failed dental restoration, overload.

\section{Concept}

Many longitudinal studies have reported osteointegrated dental implant success and survival rates of close to 90 $95 \%$. However, a broad range of failures is still observed. Implant failure may be classified as early or late. Early failures occur shortly after surgery and are characterized by lack of osseointegration. In contrast, late failures correspond to implants that have been regarded as successful for some time, and occur after prosthetic restoration has been made.
There are two main causes for late implant fracture: 1. Loss of supporting tissue secondary to infection or peri-implantitis. The prevalence of peri-implantitis is estimated to be $4-15 \%$ among the surviving implant population (i.e., implants still in the mouth).

2. Mechanical problems, including fractures. Metal fatigue due to biomechanical overloading appears to be the most frequent cause (1). 


\section{Epidemiology}

Fracture is an infrequent complication affecting two out of every 1000 implants (2-14). Those studies that make no mention of this complication usually involve a limited number of patients and implants, and follow-up is moreover typically short (15-18) (Table 1).

\section{Etiopathogenesis}

In 1996, Balshi et al. (2) carried out a study in which the possible causes of fracture were classified into three groups: 1) failure in implant design or material; 2) nonpassive fitting of the crown of the prosthetic superstructure; and 3) overloading secondary to deleterious parafunctional habits.

Both clinical and experimental research in animals have shown implant overload to induce the reabsorption of marginal bone. When such reabsorption exceeds the third implant thread apically, we reach a zone of structural weakness coinciding with the end of the prosthetic screw. This contributes to fatigue at a point where resistance to torque is smaller.

Some authors, based on in vitro studies combined with tension testing in the laboratory, have shown fractures to be caused by metal fatigue. The signs alerting to such fatigue include (3) loosening, torsion or fracture of the post screws, and ceramic fracture of the prosthesis.
These signs indicate metal fatigue, and will ultimately lead to fracture if not corrected in time.

Galvanic implant corrosion is also able to contribute to fracture.

As reported by Capodiferro et al. (19), and coinciding with our own experience, fractured implants tend to show a high percentage of contact with the bone in the fractured apical zone, probably resulting from important bone remodeling in an attempt to adapt to loading (Fig. 1).

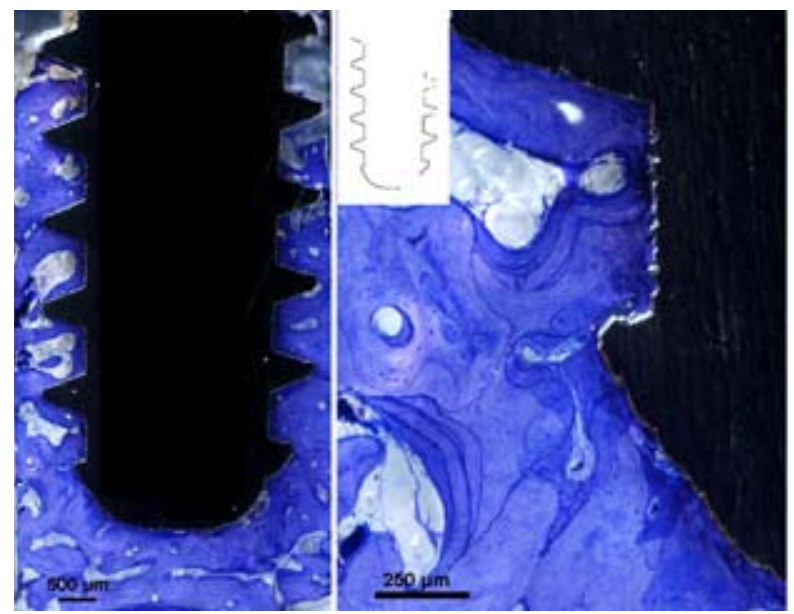

Fig. 1. Longitudinal section of the fractured implant axis,stained with toluidine blue. Note the high percentage contact between the bone and implant.

Table 1. Prevalence of implant fractures in the reviewed literature.

\begin{tabular}{|l|c|c|c|c|}
\hline \multicolumn{1}{|c|}{ Authors } & Year & Total implants & Fractured & Percentage \\
\hline Adell et al. (4) & 1990 & 4636 & $\begin{array}{c}139 \text { mandible } \\
278 \text { maxilla }\end{array}$ & $\begin{array}{c}3 \% \text { mandible } \\
6 \% \text { maxilla }\end{array}$ \\
\hline Zarb \& Smitt (16) & 1990 & 274 & 0 & $0 \%$ \\
\hline Jemt (15) & 1991 & 391 & 0 & $0 \%$ \\
\hline Tolman \& Laney (5) & 1992 & 1778 & 3 & $0.16 \%$ \\
\hline Jemt \& Lekholm (6) & 1993 & 259 & 1 & $0.38 \%$ \\
\hline Mericske-Stern (7) & 1994 & 66 & 1 & $1.51 \%$ \\
\hline Jemt \& Lekholm (17) & 1995 & 801 & 0 & $0 \%$ \\
\hline Rangert et al. (3) & 1995 & 10,000 & 39 & $0.39 \%$ \\
\hline Takeshita et al. (9) & 1996 & 68 & 5 & $7.35 \%$ \\
\hline Balshi (2) & 1996 & 4045 & 8 & 0.19 \\
\hline Lekholm et al. (8) & 1999 & 461 & 3 & $2.7 \%$ \\
\hline Davis \& Packer (10) & 1999 & 52 & 2 & $3.8 \%$ \\
\hline Eckert et al. (11) & 2000 & 4937 & 28 & $0,6 \%$ \\
\hline Gotfredsen \& Karlsson (18) & 2001 & 133 & 0 & $0 \%$ \\
\hline Brägger et al. (12) & 2001 & 103 & 2 & $1.9 \%$ \\
\hline Berglundh et al. (13) & 2002 & Systematic review & 159 articles & $0.08-0.74 \%$ \\
\hline Gargallo-Albiol et al. (14) & 2008 & 1500 & 21 & $1,40 \%$ \\
\hline Sanchez-Perez et al. & 2009 & 844 & 2 & $0.23 \%$ \\
\hline
\end{tabular}




\section{Clinical manifestations}

Patients may often report spontaneous bleeding and mobility. Exploration (manually or electronically) in turn confirms increased mobility, increased pocket depth and gingival indexes, and occasionally also plaque accumulation resulting from patient fear of the pain triggered by brushing (Fig. 2). Radiologically, separation of the fragments and bone loss may be seen (Fig. 3).

Complementary explorations

An X-ray study is very useful.

\section{Diagnosis}

Balshi et al. (2) reported that implant fractures are often associated with inflammatory response on the part of the mucosa surrounding the fracture site. In this context, bleeding in response to probing is frequent, and high gingival index scores are observed.

On the other hand, bone loss surrounding the implant appears to be a constant finding. In some cases this can be evidenced radiographically before actual fracture is observed. Such marginal bone reabsorption seems to be
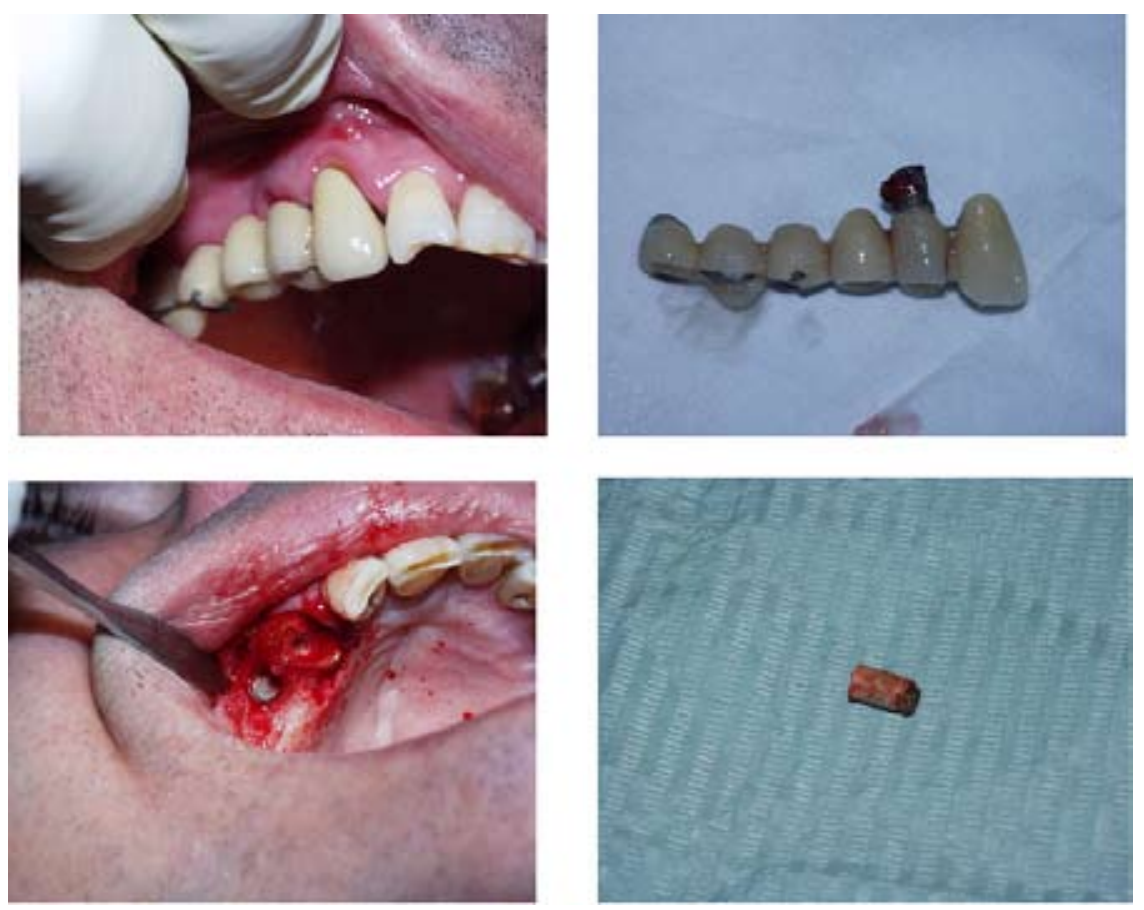

Fig. 2. Clinical examination of an implant fracture patient, showing inflammation and plaque accumulation. Trephine explantation was carried out.
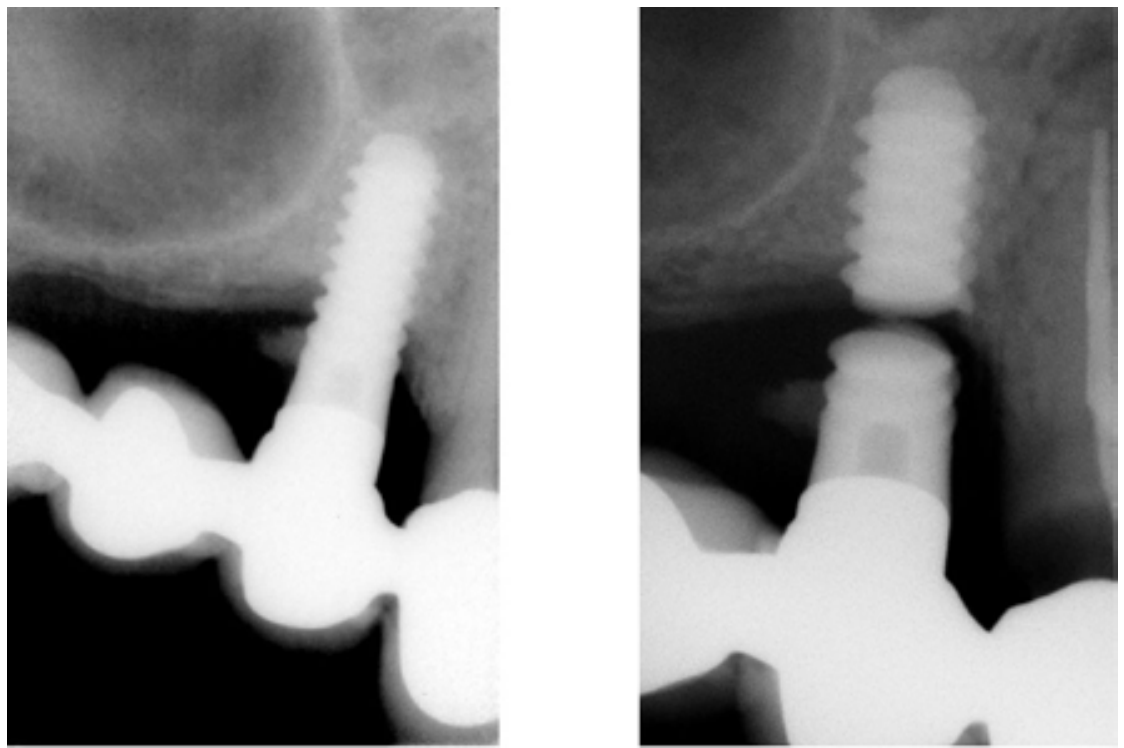

Fig. 3. Radiographic study before and after implant fracture. Note the bone loss. 
Table 2. Clinical findings frequently documented in the literature and related to implant fracture, Grouped by categories, which in the opinion of the authors constitute risk factors.

\begin{tabular}{|c|c|c|}
\hline Patient factors & Implant factors & Prosthetic fractures \\
\hline Pocket depth $>5 \mathrm{~mm}$ & Diameter $<4 \mathrm{~mm}$ & Loosening/torsion prosthesis screw \\
\hline Bone loss & Crown/implant $>1$ & Cantilevers \\
\hline Overload (bruxism) & Implants design & Ceramic fracture \\
\hline
\end{tabular}

the most important risk factor indicating the start of implant fracture, and may often extend beyond the actual fracture line.

According to McDermott et al. (20), some of the factors alerting to fracture risk are an excessive occlusal load, the location of the implant (posterior versus anterior, maxilla versus mandible), an insufficient number of implants supporting the prosthesis, the material from which the prosthetic screws are made, and an implant diameter of under $3.5 \mathrm{~mm}$.

For diagnostic purposes, we have grouped the fracture risk factors into three main categories: patient related factors, implant related factors and prosthesis related factors. In the presence of more than three factors pertaining to one or more of these categories, the risk of fracture is high (Table 2).

\section{Prognosis}

Implant fracture constitutes clear implant failure and almost always requires removal of the implant.

\section{Treatment}

Three management options have been described in the event of implant fracture $(2,15)$ :

- Complete removal of the fractured implant using explantation trephines.

- Removal of the coronal portion of the fractured implant with the purpose of placing a new prosthetic post.

- Removal of the coronal portion of the fractured implant, leaving the remaining apical part integrated in the bone.

We consider complete implant extraction to be the treatment of choice. However, when percentage of contact with bone is high, and fracture is not located too far apical, restoration of the connection between post and implant may be a valid option. To this effect, it is essential to radiologically confirm the absence of radiotransparency, and to determine mobility of the fragment electronically. This option only should be contemplated if there are still sufficient remaining internal threads to guarantee adequate prosthetic post retention (2).

\section{Conclusions}

Implant fracture is often preceded by other mechanical problems that can be interpreted as indicators of implant overload.
It is important to avoid mechanical problems and excessive bone reabsorption in order to prevent implant fracture. Special attention should focus on the number, diameter and distribution of the implants, as well as on the design of the prosthesis supported by them (reduction of cantilevers, cusp inclination and crown mesiodistal and vestibulolingual length, among other measures). When implant fracture occurs, the best management option is to remove the fragment remaining in the maxilla or mandible. The new implant replacing it should be as wide as possible, with due checking and adjustment of the occlusal forces in order to avoid overload.

\section{References}

1. Piattelli A, Scarano A, Piattelli M, Vaia E, Matarasso S. Hollow implants retrieved for fracture: a light and scanning electron microscope analysis of 4 cases. J Periodontol. 1998;69:185-9.

2. Balshi TJ. An analysis and management of fractured implants: a clinical report. Int J Oral Maxillofac Implants. 1996;11:660-6.

3. Rangert B, Krogh PH, Langer B, Van Roekel N. Bending overload and implant fracture: a retrospective clinical analysis. Int $\mathbf{J}$ Oral Maxillofac Implants. 1995;10:326-34.

4. Adell R, Eriksson B, Lekholm U, Brånemark PI, Jemt T. Longterm follow-up study of osseointegrated implants in the treatment of totally edentulous jaws. Int J Oral Maxillofac Implants. 1990;5:34759.

5. Tolman DE, Laney WR. Tissue-integrated prosthesis complications. Int J Oral Maxillofac Implants. 1992;7:477-84.

6. Jemt T, Lekholm U. Oral implant treatment in posterior partially edentulous jaws: a 5-year follow-up report. Int J Oral Maxillofac Implants. 1993;8:635-40.

7. Mericske-Stern R, Steinlin Schaffner T, Marti P, Geering AH. Periimplant mucosal aspects of ITI implants supporting overdentures. A five-year longitudinal study. Clin Oral Implants Res. 1994;5:9-18.

8. Lekholm U, Gunne J, Henry P, Higuchi K, Lindén U, Bergström $\mathrm{C}$, et al. Survival of the Brånemark implant in partially edentulous jaws: a 10-year prospective multicenter study. Int J Oral Maxillofac Implants. 1999;14:639-45.

9. Takeshita F, Suetsugu T, Higuchi Y, Oishi M. Histologic study of failed hollow implants. Int J Oral Maxillofac Implants. 1996;11:24550.

10. Davis DM, Packer ME. Mandibular overdentures stabilized by Astra Tech implants with either ball attachments or magnets: 5-year results. Int J Prosthodont. 1999;12:222-9.

11. Eckert SE, Meraw SJ, Cal E, Ow RK. Analysis of incidence and associated factors with fractured implants: a retrospective study. Int J Oral Maxillofac Implants. 2000;15:662-7.

12. Brägger $\mathrm{U}$, Aeschlimann $\mathrm{S}$, Bürgin $\mathrm{W}$, Hämmerle $\mathrm{CH}$, Lang NP. Biological and technical complications and failures with fixed partial dentures (FPD) on implants and teeth after four to five years of function. Clin Oral Implants Res. 2001;12:26-34.

13. Berglundh T, Persson L, Klinge B. A systematic review of the incidence of biological and technical complications in implant dentistry reported in prospective longitudinal studies of at least 5 
years. J Clin Periodontol. 2002;29 Suppl 3:197-212.

14. Gargallo Albiol J, Satorres-Nieto M, Puyuelo Capablo JL, Sánchez Garcés MA, Pi Urgell J, Gay Escoda C. Endosseous dental implant fractures: an analysis of 21 cases. Med Oral Patol Oral Cir Bucal. 2008;13:E124-8.

15. Jemt T. Failures and complications in 391 consecutively inserted fixed prostheses supported by Brånemark implants in edentulous jaws: a study of treatment from the time of prosthesis placement to the first annual checkup. Int J Oral Maxillofac Implants. 1991;6:270-6.

16. Zarb GA, Schmitt A. The longitudinal clinical effectiveness of osseointegrated dental implants: the Toronto study. Part III: Problems and complications encountered. J Prosthet Dent. 1990;64:185-94.

17. Jemt T, Lekholm U. Implant treatment in edentulous maxillae: a 5-year follow-up report on patients with different degrees of jaw resorption. Int J Oral Maxillofac Implants. 1995;10:303-11.

18. Gotfredsen K, Karlsson U. A prospective 5-year study of fixed partial prostheses supported by implants with machined and $\mathrm{TiO} 2-$ blasted surface. J Prosthodont. 2001;10:2-7.

19. Capodiferro S, Favia G, Scivetti M, De Frenza G, Grassi R. Clinical management and microscopic characterisation of fatigueinduced failure of a dental implant. Case report. Head Face Med. 2006;2:18.

20. McDermott NE, Chuang SK, Woo VV, Dodson TB. Complications of dental implants: identification, frequency, and associated risk factors. Int J Oral Maxillofac Implants. 2003;18:848-55. 